\title{
Análise crítica dos estudos do futuro: uma abordagem a partir do resgate histórico e conceitual do tema
}

\section{Critical analysis of future studies: an approach based on history and concepts of the topic}

\author{
Fernando José Avancini Schenatto ${ }^{1}$ \\ Édio Polacinski ${ }^{2}$ \\ Aline França de $\mathrm{Abreu}^{3}$ \\ Pedro Felipe de Abreu $^{3}$
}

\begin{abstract}
Resumo: Expandir modelos mentais, de tal modo que as condições futuras possam ser interpretadas e conformadas de maneira mais eficiente, constitui-se num desafio estratégico constante para agentes sociais, econômicos, políticos e institucionais. Nesta perspectiva, o presente artigo busca discutir os conceitos relativos aos estudos do futuro, bem como a trajetória histórica do tema, apresentando as diversas nomenclaturas e abordagens encontradas até então na literatura, caracterizando suas relações e lacunas teóricas. Para tanto, utilizando-se dos princípios do método dialético, procedeu-se um estudo teórico de finalidade descritiva, que adotou como procedimento de pesquisa a consulta bibliográfica. O estudo apresenta uma caracterização de conceitos a partir de trabalhos e autores considerados referências no tema, constituindo uma cronologia temática. Por meio de uma análise comparativa dos termos encontrados, busca-se contribuir com a construção de um arcabouço conceitual adequado à aplicação no cenário científico brasileiro acerca de estudos do futuro. Conclui-se que o tema tem origens remotas e as conceituações/nomenclaturas existentes receberam diversas contribuições, atualizando-se e ampliando suas especificações e complexidades operacionais, encontrando espaço crescente no meio científico a partir da década de 1950. A abordagem originalmente genérica tem sido substituída por visões mais específicas, relacionadas a métodos próprios de investigação e construção do futuro, ganhando maior pertinência, coerência e replicabilidade. A adoção de uma ou outra nomenclatura (e seus métodos) deve decorrer de uma identidade histórica e cultural com o contexto de aplicação. Acredita-se que essa pesquisa aponta um caminho oposto às confusões teóricas, erros conceituais ou uso amplo e indiscriminado de conceitos sinônimos, por vezes verificados na literatura, indicando ainda algumas oportunidades de desenvolvimento técnico sobre os estudos do futuro.
\end{abstract}

Palavras-chave: Estudos do futuro. Prospectiva. Prospecção. Previsão. Cenários futuros.

\begin{abstract}
Expanding mental models in order for future conditions to be interpreted and shaped more efficiently is a constant strategic challenge for social, economic, political, and institutional agents. Accordingly, this article discusses the concepts related to future studies and their historical trajectory by presenting the various classifications and approaches found in the literature characterizing their relations and theoretical gaps. Therefore, using the principles of the dialectical method, a descriptive theoretical study was conducted using literature review as the research method. This study presents a characterization of the concepts found in the studies investigated that are considered benchmark creating a timeline. Through a comparative analysis of the terms found, the focus was developing a conceptual framework suitable for the Brazilian scientific scenario concerning future studies. It was concluded that this is not a recent topic, and the existing concepts/classifications have received several contributions updating and expanding its specifications and operational complexities, since the 1950's. The originally generic approach has been replaced with more specific visions related to individual methods of investigation and future building achieving greater relevance, consistency, and replicability. The adoption of a certain classification (and its methods) must result from a historical and cultural identity with the context of application. It is believed that this research contributes to avoiding and or clearing theoretical misunderstandings, conceptual errors, or broad and indiscriminate use of synonymous concepts, which are sometimes found in the literature, presenting opportunities for future studies technical development.
\end{abstract}

Keywords: Future studies. Prospective. Foresight. Forecast. Future scenarios.

\footnotetext{
${ }^{1}$ Universidade Tecnológica Federal do Paraná - UTFPR, Via do Conhecimento, Km 1, CEP 85503-390, Pato Branco, PR, Brasil, e-mail: schenatto@utfpr.edu.br

${ }^{2}$ Faculdade Horizontina - FAHOR, Av. dos Ipês, 565, CEP 98920-000, Horizontina, RS, Brasil e-mail: edio.pk@gmail.com

${ }^{3}$ Universidade Federal de Santa Catarina - UFSC, Campus Universitário, CEP 88010-970, Florianópolis, SC, Brasil, e-mail: afdeabreu@gmail.com; pedro@deps.ufsc.br
}

Recebido em 22/4/2010 - Aceito em 24/8/2011

Suporte financeiro: Nenhum 


\section{Introdução}

A tentativa de antecipar o futuro há muito vem sendo exercitada pelas organizações, no intuito de ganhar tempo em preparar-se para superar seus competidores e, com isso, conquistar espaço na arena competitiva. Uma vez que não é possível prevê-lo de um todo, reflexões acerca de ameaças e oportunidades do porvir são suportadas e direcionadas por técnicas variadas, estudadas cada vez com maior consistência e especificidade de aplicações.

Essa ideia é reforçada pelo Instituto Nacional de Tecnologia-INT (2003, p. 1) quando se refere a que

"[...] embora o futuro seja incerto, há evidências de que as tentativas sistemáticas de ganhar perspectiva sobre o presente e possíveis situações futuras têm sido úteis."

Embora suas origens não sejam recentes, a temática dos estudos do futuro tem ganhado cada vez mais relevância no contexto organizacional e também na busca do crescimento sustentável das nações, dada a configuração da sociedade do conhecimento. Atento a essa realidade, atualmente o Brasil também intensifica esforços em iniciativas desta natureza, procurando atingir ganhos consistentes e replicáveis, de forma sistemática, a partir da perscrutação do futuro (JOHNSTON, 2001; INSTITUTO..., 2003; AMSTEUS, 2008).

Nessa perspectiva, ressalta-se que este trabalho foi desenvolvido por demanda do projeto Observatório de Desenvolvimento Industrial de Santa Catarina (ODI/ $\mathrm{SC}$ ), que previa em sua metodologia a aplicação da prospectiva estratégica de Godet ao Arranjo Produtivo Local de Tecnologia da Informação e Comunicação de Santa Catarina. Esse projeto constituiu-se em uma das seis experiências-piloto da Rede de Competências (projeto de abrangência nacional, coordenado pelo Instituto Euvaldo Lodi-IEL), que contemplava ainda a participação dos Estados do Paraná, Minas Gerais, Rio Grande do Sul, Bahia e Pernambuco, congregados pela Confederação Nacional da Indústria-CNI (OBSERVATÓRIO..., 2009), na busca pela ampliação de capacidade competitiva da indústria nacional, em segmentos específicos. A caracterização das variadas nomenclaturas e metodologias relacionadas aos estudos do futuro subsidiaram o início das atividades desse projeto, permitindo um diálogo esclarecido entre os Comitês Estaduais, a partir do correto entendimento dos conceitos relacionados ao tema.

Este artigo tem o objetivo de discutir os conceitos relativos aos estudos do futuro, apresentando as diversas nomenclaturas e abordagens encontradas na literatura, caracterizando suas relações. Pretende-se também sistematizar a trajetória histórica do tema, determinando períodos de interesse e pesquisadores de referência nas abordagens consideradas.
Para tanto, resgata-se, sucintamente, visões e aplicações desde os primórdios da humanidade. Como contraponto, no intuito de viabilizar uma discussão mais aprofundada, é dado um corte no período de tempo de maior interesse, tendo-se um maior detalhamento conceitual e de experiências empíricas da década de 1950 aos dias atuais.

Esse foco de pesquisa advém, em primeiro lugar, da importância da temática discutida, conforme já argumentado. Uma organização que não trabalhe na perspectiva do conhecimento e da inovação, pensando no futuro, já não tem mais espaço na economia vigente; quanto menos o terá na consolidação de uma nova realidade, na qual a concorrência se dará no nível da capacidade de antecipação e conformação do futuro. Tal interesse decorre ainda da possibilidade de, oferecendo à comunidade científica uma leitura analítica da evolução do tema, contribuir com a caracterização e melhor compreensão acerca das abordagens verificadas, de modo a orientar a opção por uma ou outra, conforme o interesse de um dado escopo de aplicação.

Assim, a relevância desta pesquisa reside no fato da atenção dispensada ao tema ter-se intensificado, inclusive no Brasil, seja no meio científico, seja na profusão e diversificação de aplicações. Dada a variedade de abordagens encontradas na literatura, é comum verificar-se o uso indistinto de terminologias relacionadas aos estudos do futuro, implicando em prejuízos tanto em termos de escolhas equivocadas de métodos quanto em possibilidades de comparação de resultados. Este fato é agravado ainda pelo uso concorrente de termos consagrados na literatura internacional (em inglês e francês) com suas traduções para o português. Essa adaptação terminológica por vezes promove confusões conceituais induzidas por características idiomáticas, decorrentes, por exemplo, de falsos cognatos ou de traduções literais.

A construção e difusão de um arcabouço conceitual pertinente nesta temática, associado à identificação da trajetória histórica dos conceitos envolvidos, dos períodos de interesse, bem como dos autores considerados referência em cada abordagem, vêm embasar e oferecer alguma delimitação para estudos comparativos, uma vez que permitem situar mais apropriadamente o discurso referente às abordagens e técnicas empregadas em cada caso.

Desse modo, a dialética se faz útil frente à diversidade de conceitos que se encontra na literatura, da qual emerge a necessidade de maiores esclarecimentos acerca das semelhanças e das diferenças entre os termos adotados por diversas correntes de pesquisadores e países.

Assim, o que se pretende com a apresentação dos resultados desta pesquisa não se limita à caracterização de conceitos. Espera-se, a partir da análise comparativa dos termos encontrados, contribuir com a consolidação 
de uma linguagem unificada acerca de estudos do futuro, adequado à aplicação no cenário científico brasileiro, bem como dos demais países de língua portuguesa, de modo a indicar um caminho oposto às confusões teóricas, erros conceituais ou uso indiscriminado de conceitos sinônimos, promovendo um relato mais objetivo de experiências e um melhor diálogo entre os pares.

\section{Revisão de literatura}

O futuro tem sido objeto de grande preocupação do homem, que o aborda de diferentes maneiras através da história. Dentre as interpretações mais importantes, podem-se destacar o futuro interpretado como: produto da magia; uma visão unidirecional; uma visão multidimensional e humanista (CASTRO et al., 2001 apud LIMA, 2005).

A primeira dessas abordagens interpreta o futuro como produto da adivinhação. Essa concepção perdura até nossos dias, mas predominou principalmente na época medieval, com hegemonia dos magos e feiticeiros. Já o enfoque unidirecional surgiu nos tempos modernos, com o apoio das ciências matemáticas e da estatística. Nessa compreensão, o futuro é modelado com a aplicação de modelos de projeção, utilizando séries históricas de referência. $\mathrm{O}$ terceiro enfoque surgiu no final da década de 1950, e interpreta o futuro como dependente da ação do homem, dando origem à aparição da prospectiva, sob inspiração de Berger (1964).

Com base em Godet (1982), pode-se ainda considerar os estudos do futuro divididos em duas grandes correntes: os estudos tendenciais, que utilizam projeções sobre dados do passado; e os estudos prospectivos, que consideram dados do presente. O Quadro 1 apresenta características de ambos, visando oportunizar melhor compreensão desses dois paradigmas.

Partindo desta ampla diferenciação, convém abordar as diversas nomenclaturas encontradas na literatura referindo-se a estudos do futuro, de modo a defini-las e viabilizar uma análise comparativa de enfoques e resultados potenciais. Também por decorrência dessa investigação, é possível pontuar alguns períodos históricos nos quais esses enfoques foram desenvolvidos ou mais amplamente aplicados.

\subsection{Nomenclaturas relacionadas aos estudos do futuro}

A primeira questão que surge quando se fala em estudos do futuro é terminológica.

"No Brasil, vêm sendo empregados os termos prospecção, estudos do futuro e prospectiva. Em inglês, os termos mais empregados são forecast(ing), foresight(ing) e future studies. $\mathrm{Na}$ França vêm sendo usados veille technologique, futuribles e la prospective." (INSTITUTO..., 2003, p. 6).

Acrescente-se que, muitas vezes, o termo "cenário", ou sua variação na literatura, "scenario", é usado com o mesmo sentido, embora a maioria dos autores os enquadre como uma das metodologias ou métodos usados na realização de estudos prospectivos.

A literatura disponível em português sobre o tema é reduzida. Assim sendo, as definições que seguem baseiam-se nos trabalhos que vêm sendo desenvolvidos no Brasil e, sobretudo, na literatura estrangeira. Esta, por sua vez, acaba por implicar na dificuldade em consensuar sobre um conjunto coeso de opiniões, baseado numa uniformidade terminológica. Neste contexto, conforme Fundación COTEC (FUNDACIÓN..., 2003, p. 13),

“[...] cada país tem empregado sua própria técnica de trabalho, seus objetivos futuros e os grupos de experts de cada país têm obtido, a partir das metodologias empregadas, seus próprios resultados, aparentemente diferentes."

Dada à relevância da temática, recentemente, Sardar (2010); Masini (2010) têm discutido as origens e implicações do uso das variadas terminologias, argumentando sobre a necessária aderência da opção terminológica (e sua história) ao contexto cultural da aplicação.

Quadro 1. Características dos estudos tendenciais clássicos e da abordagem prospectiva.

\begin{tabular}{|c|c|c|}
\hline Característica & Previsão ou estudo tendencial & Prospecção ou estudo prospectivo \\
\hline $\begin{array}{c}\text { Compreensão do } \\
\text { fenômeno }\end{array}$ & $\begin{array}{c}\text { Em parte } \\
\text { "Todas as demais condições iguais" }\end{array}$ & $\begin{array}{c}\text { No todo } \\
\text { "Nada permanecendo igual" }\end{array}$ \\
\hline Variáveis & Quantitativas, objetivas e conhecidas & Qualitativas, subjetivas, conhecidas ou não \\
\hline Relações & Estáticas, estruturas fixas & Dinâmicas, estruturas em evolução \\
\hline Explicação & O passado explica o futuro & O futuro é a razão de ser do presente \\
\hline Futuro & Simples e certo & Múltiplo e incerto \\
\hline Método & $\begin{array}{c}\text { Modelos determinísticos e quantitativos } \\
\text { (econométricos e matemáticos) }\end{array}$ & $\begin{array}{c}\text { Análise intencional, modelos qualitativos } \\
\text { (análise estrutural) e estocásticos }\end{array}$ \\
\hline Atitude em relação ao futuro & Passiva e adaptativa (o futuro emerge) & Ativa e criativa (o futuro é construído) \\
\hline
\end{tabular}

Fonte: Adaptado de Godet (1982). 
Embora não se pretenda restringir o uso das diversas expressões conhecidas, cabe uniformizar o entendimento de seus significados, de modo que estudos comparativos possam ser realizados sem incorrer em erros decorrentes de inadequações conceituais. Nesse contexto, o trabalho prossegue introduzindo as nomenclaturas e definições relacionadas ao tema.

\subsubsection{Future studies}

Constitui um termo amplo que abrange todas as atividades relacionadas à melhora da compreensão sobre as consequências futuras dos desenvolvimentos e das escolhas atuais (AMARA; SALANIK, 1972). Também se pode dizer que é um campo multidisciplinar, relacionado a uma variada gama de visões sobre os futuros possíveis, prováveis ou preferenciais (ASSAKUL, 2003 apud INSTITUTO..., 2003).

Neste sentido, entende-se future studies como um termo genérico, que abarca todas as variantes de estudos e métodos propostos na tentativa de antecipar e/ou construir o futuro.

\subsubsection{Estudos do futuro}

Para Gonçalves (2007), apesar do interesse do homem em conhecer o futuro acompanhá-lo desde os primórdios da humanidade, o campo de investigação conhecido como "estudos do futuro" surgiu somente há quase cinquenta anos. Masini (2002) considera que esses estudos iniciaram-se na década de 1960, quando, após o impacto da Segunda Guerra Mundial, estudiosos se interessaram em pesquisar o tema em nível global.

Existe um sem-número de visões relacionadas aos estudos do futuro, dentre as quais se destacam: interação de tendências históricas e a ocorrência de eventos de grande complexidade, de múltiplas interações entre sistemas sociais, e de fenômenos sociais e políticos (JOHNSON, 1969); estudos sobre a confluência de muitas forças passadas, presentes e futuras, que podem ser mais bem entendidas com base na reflexão (SCHNAARS, 1987); futuro como algo inexistente e inatingível, porque quando é chegado o porvir, chega-se ao presente, e não ao futuro (MARINHO; QUIRINO, 1995).

Desde o surgimento dos estudos do futuro como campo de pesquisa acadêmica, depois da Segunda Guerra Mundial, estes se tornaram searas trans/ multidisciplinares de pesquisa, com uma diversidade de escolas, métodos, abordagens e aplicações de pensamento. Essa visão de Patokorpi e Ahvenainen (2009) é sistematizada no Quadro 2.

Uma análise do Quadro 2 permite observar a amplitude da identidade terminológica utilizada, denotando perspectivas filosóficas e metodológicas variadas. Ao passo que alguns autores adotam variantes de uma mesma abordagem, outros são identificados por empreenderem esforços sob paradigmas complementares ou até mesmo opostos, visando abarcar um maior repertório de métodos e técnicas, adequados para aplicações diversas.

Masini e Samset (1975) indicam que os estudos do futuro constituem um campo da atividade intelectual e política, relacionados a todos os setores da vida social, econômica, política e cultural. Visam descobrir e dominar as complexas cadeias de causalidades, por meio de conceitos, reflexões sistemáticas, experimentações, antecipações e pensar criativo, tendendo a transformar-se em novos foros para a tomada de decisão e formulação de políticas. Disso decorre a afirmação de Coates (2003), quando diz que o objetivo básico de estudar o futuro é mudar a mente e depois o comportamento das pessoas.

É comum aos estudos acadêmicos a tese de que o mundo real é muito complexo para que se possa desvendar o seu eventual determinismo oculto. E mesmo que isto fosse possível, a incerteza inerente às variáveis manteria sempre em aberto a possibilidade de vários futuros. É o que afirmam Godet (2000); Gordon (2004); Camargo (2005), dentre outros.

Assim,

"[ ] ] ao assumir o pressuposto de que o futuro não pode ser controlado, mas a sociedade pode influenciá-lo, o homem buscou, então, desenvolver e testar diversas metodologias para explorar, criar e provar, sistematicamente, pelo menos duas visões de futuro: a possível e a desejável."(GLENN, 2004, p.8).

Quadro 2. Orientações conceituais e metodológicas sobre estudos do futuro.

\begin{tabular}{|l|l|}
\hline Defensores de escolas de pensadores & \multicolumn{1}{c|}{ Orientação } \\
\hline Gaston Berger, Bertrand de Jouvenel & Prospectiva, futurible \\
\hline Roy Amara & Provável, possível, preferível \\
\hline Jurgen Habermas (Richard Slaughter) & Técnica, hermenêutica/(prática), emancipatória \\
\hline Eleonora Barbieri Masini & Extrapolativa, utópica, visionária \\
\hline Sohail Inayatullah & Empírica preditiva, interpretativa cultural, crítica pós-estruturalista \\
\hline Wendell Bell & Positivista, realista crítica, pós-positivismo \\
\hline Mika Mannermaa & Descritiva, paradigma de cenários, evolucionária \\
\hline
\end{tabular}

Fonte: Traduzido de Patokorpi e Ahvenainen (2009, p. 128). 
Com base nisso, é possível aceitar que esta denominação sobrepõe-se exatamente à definição anterior (future studies). Evidencia-se, no entanto, que este tratamento mais genérico utilizado para definição de "estudos do futuro" tem sido substituído por visões mais específicas, relacionadas a métodos próprios de investigação e construção do futuro.

\subsubsection{Antecipação e previsão}

Decisões baseiam-se na expectativa de realização de um evento ou conjuntura. Assim, pode-se dizer que decidir é posicionar-se em relação ao futuro.

Dependendo do prazo disponível para a tomada de decisão e do volume de informações passíveis de obtenção nesse prazo, o indivíduo estará entre dois estados: de certeza, quando sua decisão é única e tem caráter determinístico; ou de incerteza, quando dependerá de um conjunto de hipóteses, assumindo caráter probabilístico (SANTOS, 2004). Ainda, para o autor, o futuro, além de inevitável, é incerto. Contudo, é possível prever certos eventos, como consequência de atos e decisões passadas ou sujeitas a um calendário regular.

Entre as técnicas de previsão, de acordo com Bodini (2001), existem os modelos extrapolativos e os métodos de prospecção (exploratórios).

Com relação aos modelos extrapolativos, Godet (2003) destaca: previsão - é a avaliação, com certo grau de confiança (probabilidade), da evolução de uma grandeza num dado horizonte, para a qual se propõem hipóteses futuras a partir de dados coletados no passado; projeção - é o prolongamento de uma evolução passada, segundo hipóteses de extrapolação ou inflexão de tendências, constituindo-se em previsão se contiver probabilidade.

Observa-se na literatura que as técnicas extrapolativas são vistas hoje como mais simples, no que se refere ao entendimento conceitual e em relação à aplicação de casos práticos. Por conta disso, tornaram-se muito difundidas entre profissionais nas diversas áreas de conhecimento. Por outro lado, Bodini (2001) evidencia que, apesar da simplicidade e disseminação, tais modelos nem sempre se apresentam como bons recursos de previsão, pois muitas vezes necessitam ser complementados com o uso de outras técnicas e abordagens. Isso ocorre porque, em geral, os modelos de previsão exigem uma série de dados que partem da premissa de que o futuro será parecido com o passado, o que, na prática, nem sempre ocorre.

Além disso, sabe-se que na maioria das vezes os bancos de dados, quando existem, são pouco confiáveis, incompletos ou sem periodicidade de atualização, com unidades de medidas diferentes e com poucos dados relevantes ao estudo. Na prática, porém, a extrapolação sobre tendências passadas depende, sobretudo, de dados históricos confiáveis, que devem cobrir um período relativamente longo, de preferência maior que o período de tempo que se está projetando, e com padrões uniformes de coleta ao longo do tempo (BODINI, 2001).

Apesar de apresentar aplicações limitadas ou, em muitos casos, dever ser substituída por alternativas mais adequadas, essa abordagem trouxe contribuições históricas ao tema. Reflexões dessa natureza permitiram uma melhor adequação de metodologias e ferramentas aos objetos de estudo, levando, por consequência, à definição de novos conceitos.

Assim sendo, este trabalho associa os termos "antecipação" e "previsão" a um porvir tendencial, que pode ser analisado por meio de séries históricas, aplicando-se ferramentas matemáticas. A alternativa exploratória supracitada apresenta maior aderência à abordagem prospectiva, ou de prospecção, tratadas a seguir.

\subsubsection{Prospecção}

Segundo Cuhls e Grupp (2001), a prospecção pode ser definida como:

"Processo que se ocupa de procurar, sistematicamente, examinar o futuro de longo prazo da ciência, da tecnologia, da economia e da sociedade, com o objetivo de identificar as áreas de pesquisa estratégica e as tecnologias genéricas emergentes que têm a propensão de gerar os maiores benefícios econômicos e sociais."

Embora restrinja o foco a longo prazo, essa definição é abrangente quanto aos setores de aplicação. Também se destaca que, de forma subjetiva, considera o processo de tomada de decisão como aspecto central da prospecção. Esse mesmo fator é apresentado de forma explicita na abordagem de Marcial e Grumbach (2006), para os quais a prospecção é um processo continuado de pensar o futuro e de identificar elementos para a melhor tomada de decisão, considerando aspectos econômicos, sociais, ambientais, científicos e tecnológicos.

A mesma visão é compartilhada pelo Instituto Nacional de Tecnologia (2003), para o qual prospecção não é a mesma coisa que prognóstico ou previsão, mas sim, apresenta a ideia de se ter uma participação ativa na conformação do futuro. Nessa perspectiva, Bodini (2001) acrescenta que os métodos de prospecção utilizam basicamente dados qualitativos, definidos por especialistas, profissionais e pesquisadores da área, por meio dos quais se procura identificar acontecimentos e ações que possam promover uma situação futura melhor definida.

Já quanto a suas características, de acordo com Godet (1982), os estudos de prospecção envolvem: compreensão do fenômeno (considera o todo, no qual nada permanece igual); variáveis (qualitativas, não 
necessariamente quantificáveis, subjetivas, conhecidas ou ocultas); relações (dinâmicas, com estruturas em evolução); explicação (o futuro é a razão de ser do presente); futuro (múltiplo e incerto); método (de análise intencional, com modelos qualitativos e estocásticos); e atitude em relação ao futuro (ativa e criativa).

Por constituir-se no principal enfoque dado aos exercícios prospectivos, apresentam-se também definições de prospecção tecnológica, visando ampliar a compreensão sobre o tema.

Prospecção tecnológica é o termo aplicado aos estudos que têm por objetivo antecipar e entender as potencialidades, evolução, características e efeitos das mudanças tecnológicas, particularmente sua invenção, inovação, adoção e uso (COATES et al., 2001). Já para Kupfer e Tigre (2004), prospecção é o meio sistemático de mapear os desenvolvimentos científico e tecnológico futuros, capazes de influenciar de forma significativa uma indústria, economia ou sociedade.

Partindo dessas visões, adota-se no escopo deste trabalho a orientação de que "prospecção" envolve métodos com viés exploratório ou normativo, nos quais a reflexão coletiva sobre os desafios futuros para a tomada de decisão levam em consideração aspectos econômicos, sociais, ambientais, científicos e tecnológicos, sendo frequentemente associados à grande temporalidade. Conduz à definição de opções estratégicas que priorizam a abordagem qualitativa na análise do futuro.

\subsubsection{Prospectiva}

Godet (2000) afirma que a prospectiva é um instrumento que possibilita à organização a estruturação, por meio de uma reflexão coletiva dos desafios futuros, e, eventualmente, a avaliação das opções estratégicas. Contudo, salienta que existem estudos prospectivos que não têm caráter estratégico bem definido, como também existem análises estratégicas que são realizadas sem considerar algum tipo de investigação aprofundada em prospectiva, ou até mesmo são omissas a esse tipo de estudo.

Para Lima (2005), a prospectiva, atualmente, é uma das ferramentas mais poderosas e sofisticadas à disposição dos gestores no que se refere à compreensão do futuro. Além disso, a análise prospectiva é uma base sólida para a sustentabilidade institucional, uma vez que permitirá a compreensão e percepção, de forma sistemática, do comportamento de variáveis do ambiente organizacional, que são relevantes para a definição de rumos e estratégias.

No intuito de atingir uma melhor adequação terminológica, diferenciam-se brevemente dois enfoques dados por Godet (2001) à prospectiva: estratégico - alia a prospectiva à formulação de estratégias, uma vez que é necessário construir-se atitudes face ao futuro; territorial - é relacionado à concretização dos objetivos e definição de um planejamento estratégico global para o território (região ou cidade).

Sinteticamente, pode-se dizer que "prospectiva" é uma abordagem sobre o futuro na qual a reflexão coletiva sobre os desafios para a tomada de decisão conduz à definição de opções estratégicas, que priorizam a abordagem qualitativa, implicando na coesão de esforço dos envolvidos na definição do futuro desejado e na conjugação de ações para torná-lo exequível.

\subsubsection{Foresight}

Uma tradução para o termo foresight é antevisão, porém, também poderia usar-se prospecção. Contudo, vale referir-se ao termo em inglês para marcar sua raiz teórica, advinda da abordagem evolucionista da teoria econômica (ZACKIEWICZ; SALLES FILHO, 2001).

O foresight parte da premissa de que o futuro não está e não pode ser determinado analiticamente. A perspectiva é outra: precisão só seria importante se os atores envolvidos não pudessem influenciar o produto final gerado no processo, o que não é o caso. A abordagem prevê a construção interativa do futuro em uma sucessão de visões e interpretações desse futuro, que vão sendo aperfeiçoadas ou mesmo superadas por outras mais adequadas e consistentes com o entorno (ZACKIEWICZ; SALLES FILHO, 2001).

Coates (1985) refere-se ao termo como o processo pelo qual se pode chegar a um entendimento mais completo das forças que moldam o futuro a longo prazo e que devem ser levadas em consideração na formulação de políticas, planejamento e tomadas de decisão.

Em síntese, "foresight implica em negociar demandas e campos promissores de investigação, mas também em atuar nas condições do ambiente no qual estão inseridos os atores, promovendo uma macrocoordenação" (ZACKIEWICZ; SALLES FILHO, 2001, p. 145).

Os mesmos autores ainda afirmam que inclui meios qualitativos e quantitativos para monitorar pistas e indicadores de tendências de desenvolvimento e seu desenrolar, e é melhor e mais útil quando diretamente ligado à análise de políticas e suas implicações.

Linstone e Grupp (1999) identificam quatro dimensões nas quais esta abordagem pode desempenhar um papel relevante: sócio-política; econômica; cultural; e diplomática.

Segundo Horton (1999) o sucesso de exercícios de foresight depende de um processo sucessivo de construção do conhecimento que se constitui de três 
fases: i) coleta de informações - organização e resumo das informações disponíveis sobre determinada demanda, identificação de especialistas e mapeamento dos atores; ii) realização do exercício propriamente dito - são aplicadas metodologias que promovam a interação entre os atores na discussão de temas levantados na fase anterior, quando ocorrem interpretações e traduções a respeito das tendências atuais e possibilidades futuras; iii) tomada de decisões e implementação de ações - procura-se fortalecer o comprometimento dos participantes das fases anteriores, mediante processo de validação e legitimação das decisões e ações.

De modo semelhante à prospecção, o foresight também tem sua vertente tecnológica. É o technological foresight, que equivale à prospectiva tecnológica e seu objetivo é determinar características das tecnologias relacionadas com as demandas de futuros possíveis, prováveis ou desejados. Pode levar à identificação das prioridades atuais em C\&T, à luz das projeções hipotéticas de futuros desenvolvimentos econômicos e sociais (FUNDACIÓN..., 2003).

Por fim, ampliando a discussão para o escopo dos aglomerados produtivos, Roveda e Vecchiato (2008) discutem a dinâmica de inovação nos clusters, dizendo que oforesight direciona os pequenos empreendedores, os stakeholders do aglomerado, e as firmas médias e grandes a atuar nos papéis críticos do modelo de empresa do conhecimento de Nonaka e Takeuchi, respectivamente, os empregados de baixo escalão, gerentes sênior e intermediários.

Nessa perspectiva, define-se foresight regional, que se refere à implementação de antecipação, participação, ligações em rede, visão e ação em uma escala territorial reduzida, em que fatores relacionados à proximidade se tornam determinantes. Além disso, diz respeito à aplicação de métodos prospectivos com o propósito de informar e orientar as decisões tomadas em nível subnacional (uma região, um Estado federal, uma área metropolitana, qualquer outra agregação subnacional, ou mesmo um sistema local de atores). O importante é que haja um grau mínimo de identidade local e de poder político disponível (FORESIGHT..., 2001).

Diante do exposto, define-se "foresight" como um método qualitativo, com objetivo de envolver todos os atores na definição do futuro desejado e na conjugação de esforços para torná-lo exequível, visando sempre identificar os elementos mais apropriados para a melhor tomada de decisão, levando em consideração aspectos econômicos, sociais, ambientais, científicos e tecnológicos, com viés exploratório ou normativo, no qual a reflexão coletiva sobre os desafios futuros conduzem à definição de opções estratégicas.

\subsubsection{Forecast}

Skumanich e Silbernagel (1997 apud INSTITUTO..., 2003 , p. 7) afirmam que as definições de forecast coincidem com as de foresight. Buscando uma diferenciação, dizem que:

Embora tanto foresighting quanto forecasting envolvam a tentativa de estimar as condições futuras baseadas no presente, o segundo termo inclui, também, a conotação de previsibilidade; à medida que os métodos se aprimoram, forecasting deve se tornar cada vez mais preciso na estimativa de estados futuros. Em contraste, um tema recorrente em foresighting é que muitos aspectos relacionados ao futuro não são previsíveis e, portanto, a "precisão" torna-se um conceito menos relevante.

Essa afirmativa denota que os autores não distinguem os conceitos em termos de suas finalidades, mas sim quanto instrumental metodológico associado a eles. Tratar forecast e foresight desta forma, indistinta, pode conduzir a discursos equivocados e comparações mal conduzidas, por tratarem de abordagens divergentes, embora eventualmente complementares.

Por sua vez, Amara e Salanik (1972) apresentam uma definição progressiva para forecasting, relacionada ao grau de precisão que os estudos podem apresentar: uma indicação sobre o futuro; uma indicação probabilística sobre o futuro; uma indicação probabilística, razoavelmente definitiva sobre o futuro; e uma indicação probabilística, razoavelmente definitiva sobre o futuro, baseada em uma avaliação de possibilidades alternativas.

Mais recentemente, Salles Filho et al. (2001) destacam que forecasting possui uma conotação próxima de predição, remontando a uma tradição envolvida prioritariamente com a construção de modelos para definir as relações causais dos desenvolvimentos científicos e tecnológicos e esboçar cenários probabilísticos do futuro. Ressalte-se que uma vez que a aplicação mais recorrente de estudos dessa natureza tem sido a investigação acerca do desenvolvimento tecnológico, essa particularidade pode ser definida de forma específica.

Apresentando também a mesma ênfase sobre tecnologia que as denominações anteriores, Porter et al. (1991) designam technological forecasting como as atividades de prospecção que têm foco em mudanças na tecnologia. Normalmente é centrada em mudanças na capacidade funcional, no tempo e significado de uma inovação.

Fazendo uma comparação com conceitos semelhantes, a Fundación COTEC afirma que technological forecast equivale à previsão tecnológica e seu fim é prever o estado futuro de uma tecnologia e a extensão de seu uso. Seu objetivo é a predição 
probabilística dos futuros desenvolvimentos tecnológicos (FUNDACIÓN..., 2003).

Essa abordagem não só corrobora a visão anteriormente exposta, acerca do aspecto da predição probabilística, como também auxilia na identificação da sobreposição de conceitos.

Com base nessa argumentação, adota-se a visão de que forecast refere-se à definição de um porvir tendencial, que pode ser estimado aplicando-se ferramentas matemáticas na análise de séries históricas. Quanto mais confiáveis forem as bases de dados e mais amplo o período de tempo que elas contêm registros, mais confiável será esta extrapolação.

\subsubsection{Technology assessment}

Refere-se à avaliação tecnológica. Seu fim é a análise das consequências de aplicar determinada tecnologia, incluindo os efeitos secundários que possam surgir. Para Fundación COTEC (2003, p. 20), "[...] visa antecipar os impactos que a aplicação das tecnologias existentes, e de novas tecnologias, pode gerar no futuro".

Blair (1994) afirma que technology assessment é um conceito que começou a ser aplicado pelo Office of Technology Assessment (OTA), nos Estados Unidos, em 1972, a partir da constatação de que a tecnologia muda e se expande rápida e continuamente. Suas aplicações são amplas e em escalas crescentes, cada vez mais generalizadas e críticas em seus impactos, benefícios e problemas em relação ao ambiente social e à natureza.

Vale ressaltar que, desde então, passou a ser essencial que as consequências das aplicações tecnológicas sejam antecipadas, compreendidas e consideradas na determinação das políticas públicas em problemas existentes e emergentes. Ainda, que technology assessment busca fornecer indicações antecipadas dos benefícios prováveis ou impactos adversos das aplicações de uma tecnologia (BLAIR, 1994).

Com base nesses autores, technology assessment é visto neste trabalho como uma forma de acompanhar e estimar trajetórias tecnológicas, envolvendo métodos que permitem antecipar alternativas e consequências do desenvolvimento. Assim, enfoca a análise de impacto das tecnologias vigentes e futuras, constituindo-se mais em radar do que em ação.

\subsubsection{Veille technologique}

"É a observação e análise da evolução científica, técnica, tecnológica e de impactos econômicos reais ou potenciais correspondentes, para identificar as ameaças e as oportunidades de desenvolvimento da sociedade" (JAKOBIAK, 1997 apud INSTITUTO..., 2003, p. 9).
Dessa forma, a compreensão sobre veille technologique sobrepõe-se à anterior (technology assessment), apresentando caráter mais diagnóstico (ex-post e ex-ante) do que pró-ativo sobre o desenvolvimento tecnológico, manifesto na análise dos impactos sociais e econômicos dele decorrentes.

\subsubsection{Futuribles}

O termo foi criado por Bertrand de Jouvenel e está relacionado aos futuros possíveis (JOUVENEL, 2000).

Os futurólogos designam com a palavra futuribles os futuros que se podem vislumbrar, deixando o nome futurables para aqueles que, dentre esses, são mais prováveis de acontecer. Essa análise resulta da interação de numerosos fatores e variáveis (GRONDONA, 2007).

Assim, visando compatibilizar essa sutil diferença idiomática, pode-se definir futuribles como representações do futuro, possíveis ou prováveis (este como subgrupo do primeiro).

\subsubsection{La Prospective}

Bouvier (2002) aponta que o termo La Prospective data de 1957, cunhado por Gaston Berger. Seu grande teórico, no entanto, é Michel Godet, segundo o qual a tradução mais próxima de prospective é foresighting, embora a noção de pró-atividade esteja menos presente neste último, segundo ele. Prospective não é apenas um enfoque exploratório (antecipação estratégica), mas representa também um enfoque normativo (desejado).

Godet (1986) aponta a La Prospective como uma análise qualitativa que não pode ser definida como forecasting, tampouco como futurologia. $\mathrm{O}$ autor define La Prospective como um modo de pensar baseado na ação e não na predeterminação, usando métodos específicos.

A prospective enfatiza a importância da inserção do pensamento alternativo e de longo prazo no processo decisório, bem como pode ser relacionada ao espaço em que os sonhos fertilizam a realidade, o desejo é a força produtiva do futuro e a antecipação ilumina o pré-ativo e o pró-ativo. Para qualquer organização, prospective não é filantropia, mas sim reflexão com vistas a clarificar a ação, especialmente a ação de natureza estratégica (GODET, 2000).

Face ao exposto, observa-se que a atitude prospectiva não consiste em esperar a mudança para reagir, mas sim controlá-la em duplo sentido, preparar-se para uma mudança esperada, mas agir em pró-atividade, com o intuito de provocar uma mudança desejada.

Godet (1986) apresenta sete ideias-chave que constituem a base do enfoque de La Prospective e da técnica de cenários: clarear as ações presentes à luz do futuro; explorar futuros múltiplos e incertos; 
adotar um enfoque global e sistemático; levar em consideração fatores qualitativos e as estratégias dos atores; lembrar sempre que a informação e a prospecção não são neutras; optar por uma pluralidade e complementaridade de enfoques; questionar ideias pré-concebidas sobre prospecção e sobre quem trabalha na área.

Diante disso, entende-se La Prospective como uma metodologia qualitativa, em que a reflexão coletiva sobre o futuro orienta a definição das opções estratégicas que oportunizam a tomada de decisões relativas a um tema/problema sob investigação, com base na opinião, expectativas e interesses dos atores envolvidos.

\subsubsection{Cenários}

Embora não possa ser classificado propriamente como um método de estudo do futuro, como os demais até então expostos, a técnica de cenários é amplamente utilizada como ferramenta para essa finalidade, de modo que, muitas vezes, se confunde com o próprio método. Assim, justifica-se o interesse em discuti-la.

De acordo com Schwartz (1996 apud OLIVEIRA, 2001), cenários são definidos como instrumentos para ordenar percepções sobre ambientes futuros alternativos, sobre as quais as decisões atuais se basearão, sendo que, na prática, cenários se assemelham a um jogo de histórias, escritas ou faladas, construídas sobre enredos desenvolvidos cuidadosamente. O método de construção de cenários busca construir representações do futuro, assim como rotas que levam até essas representações, que buscam destacar as tendências dominantes e as possibilidades de ruptura no ambiente em que estão localizadas as organizações e instituições.

Rattner (1979) observa que a construção de cenários visa a um procedimento sistemático para detectar as tendências prováveis da evolução, em uma sequência de intervalos temporais, bem como procura identificar os limites da tensão social nos quais as forças sociais poderiam alterar essas tendências.

Cabe também considerar a visão de Godet e Roubelat (1996), na qual os cenários representam uma descrição de uma situação futura, bem como do conjunto de eventos que conduzirão da situação original para uma situação futura, em que o futuro é múltiplo. Para os autores, o caminho que leva a um futuro, ou outro, não é necessariamente único, ainda que a descrição de um futuro potencial, e a progressão em direção a ele, represente um cenário.

Por conta dessas alternativas, os mesmos autores classificam os cenários em exploratórios; e desejados, antecipatórios ou normativos. Já Borjeson et al. (2005) fazem três outras distinções: o cenário projetivo mostra o que irá ocorrer; o prospectivo expõe o que pode ocorrer; enquanto o normativo indica como atingir um objetivo específico.

Por fim, de acordo com Wright (2005), a construção de cenários é uma abordagem de pensamento estratégico que reconhece a imprevisibilidade do futuro, devendo ser utilizada como ferramenta para delimitar os caminhos possíveis de evolução do presente.

Tomadas por referência essas considerações, cenários, no contexto deste trabalho, devem ser vistos como representações do futuro (possível ou provável, desejado ou não) tomadas como ferramenta administrativa, e não como previsão. O propósito não é acertar a descrição do futuro, e sim orientar a tomada de decisões estratégicas referentes aos eventos e caminhos alternativos de sua configuração ou construção.

\subsection{Trajetória histórica dos estudos do futuro}

Chrispino (2001) aponta que o interesse pelo futuro perde-se na história do homem, na qual se percebe a busca pelo seu desvelar em numerosas civilizações antigas. Um exemplo disso é dado por Schwartz (1991), quando se refere aos sacerdotes do Nilo sudanês como os primeiros previsores do futuro de longo prazo.

Os primeiros "construtores" de futuro de que há registros foram os profetas presentes nas religiões judaica, cristã e islâmica. Esses importantes personagens da história tiveram um papel preponderante de conselheiros, não pretendendo ser meros adivinhos.

Além da Grécia antiga, onde o futuro era "predito" nos oráculos, de acordo com Jaguaribe (1996), os estudos do futuro, posteriormente, passaram a ter importância para o Império Romano, que tinha a obsessão da previsão do futuro, cujos processos eram praticados até a já avançada República. Vem a prática divinatória, portanto, desde o período da Roma monárquica até o tempo de Cícero.

Os romanos tinham dois grandes tipos de adivinhação do futuro supostamente válidos: aquele que eles herdaram dos etruscos - o haruspicius, que se caracterizava pelo exame das entranhas de certos animais; e aquele que era dotado de mais credibilidade, no qual se observava o vôo de pássaros. Este não era voltado para cenários macroscópicos, mas para o provável resultado de certa ação imediata (JAGUARIBE, 1996).

A preocupação com o futuro ressurge com o Renascimento e toma importante forma literária com Júlio Verne no Século XIX. Já no início do século XX, destacam-se os pensadores George Wells, Vernon Lee e Berthand Russel. Nos anos 30, outra obra literária torna-se famosa: o "Admirável Mundo 
Novo", ficção de Aldous Huxley. A obra de Verne inspira e direciona o futuro, que reproduz a sua arte. No caso de Huxley, a tecnologia caminha na direção apontada no livro e o alerta sobre a questão política foi, seguramente, importante instrumento para guiar o futuro numa direção melhor (CRISTO, 2002).

Para Godet (1993), Gaston Berger relançou nos anos 60 a palavra prospectiva, retirando-lhe do conteúdo a força da previsão que estava demasiado impregnada de profecia.

Cristo (2002) destaca ainda que as duas guerras do século passado e sua herança, a Guerra Fria, incitaram ao desenvolvimento de instrumentos de planejamento para além dos planos quinquenais, sendo menos determinísticos e mais probabilísticos, buscando evitar situações das quais se poderia não ter retorno, dada a capacidade de autodestruição adquirida pela humanidade. Nessa perspectiva surgem a Rand Corporation e, posteriormente, o Hudson Institute, como centros de referência de estudos prospectivos.

Nesta mesma década notabilizaram-se personalidades como Herman Kahn e Michel Godet, além de trabalhos como o World Dynamic, sobre sistema ecológico, e o estudo prospectivo da Shell. Acrescente-se que por meio deste último, em 1969, foi possível identificar um cenário futuro relacionado a um possível "choque do petróleo", o que levou a organização a obter petróleo nas águas do Mar do Norte, antes das demais concorrentes, alçando-a ao segundo lugar no ranking de sua indústria.

Fazendo uma complementação a partir de Chrispino (2001), sabe-se que a popularização dos estudos sobre o futuro alcançou também o meio acadêmico. No início da década de 60, Richard Meier iniciou grupos sistemáticos de estudos de futuro na Universidade de Michigan e, depois, na Universidade da Califórnia, em Berkley. Identificam-se também alguns importantes autores que contribuíram na disseminação da visão do futuro e da importância de pensar o futuro como fator de decisão atual, dentre os quais se destacam Frederick Polak, Benjamin Singer e Victor Frankl.

Enfim, Marcial e Grumbach (2006) representam um interessante caminho de construção histórica da prospectiva no século $\mathrm{XX}$, quando identificam as principais obras e eventos relacionados com estudos de futuro. Destacam-se:

- a obra do escritor inglês George Wells, "História do futuro" que analisa os avanços tecnológicos ocorridos ao final do século XIX e a ascensão dos EUA, do Japão e da Rússia na política internacional, escrita em 1902;

- a famosa obra "Admirável mundo novo", de Aldous Huxley escrita em 1930;

- as declarações de Einstein sobre energia e do cientista alemão George Picht sobre corrida armamentista, feitas durante a II Guerra Mundial;
- o fortalecimento da prospectiva militar (EUA) e econômica (Europa) no pós-guerra;

- os trabalhos de Gaston Berger, sobretudo a obra "A atitude prospectiva", escrita em 1957 e de Herman Khan, que atuou na Rand Corporation durante os anos 50;

- a criação do Centro de Prospectiva do Instituto Hudson, do qual Herman Kahn, egresso da Rand Corporation, foi diretor, que pesquisa prospectiva geográfica clássica e publicou a obra "The year 2000" escrita em 1967, na qual a palavra cenários foi introduzida;

- a criação do Masachussets Institute of Technology, no qual James Forretre desenvolveu pesquisa em torno do sistema ecológico denominado World Dynamic;

- a criação do Institute for the Information Society, do Japão, que, por meio de um projeto, desenhou a substituição da sociedade industrial pela sociedade informatizada;

- na década de 70, os estudos realizados por americanos para a construção de cenários baseados em reuniões de peritos (método Delphi e Matriz de Impactos Cruzados);

- os importantes trabalhos sobre cenários, inspirados na Escola Francesa de Prospectiva, desenvolvidos por Pierre Wack que trabalhou na Royal Dutch Shell;

- já na década de 80 , com a forte expansão dos estudos prospectivos, destacam-se os trabalhos dos norte-americanos Bell, Kahnemann, Tverski, Schwartz, Porter e Godet.

- a popularização do emprego de cenários como ferramenta estratégica, iniciada, sobretudo, com a Global Business Network (GBN), criada por Schwartz e Wack.

Santos (2004) professa que fatores conjunturais e o avanço tecnológico forçaram o desenvolvimento de novas metodologias que viabilizassem planejamentos de médio e longo prazo, com participação ativa na construção do futuro, em condições dinâmicas de mudança nos processos decisórios. A partir da obra de Berger (1957), surge a mudança definitiva de mentalidade de um futuro único (previsão clássica) para os vários futuros possíveis (prospectiva). O porvir passou a ser encarado como algo que não está predeterminado, mas em processo de elaboração, podendo-se interferir no seu curso por meio de ações desenvolvidas no presente. $\mathrm{O}$ autor acrescenta que surgem, então, o Centre d'Études Prospectives, na França, e o Hudson Institute, nos Estados Unidos, que propiciaram as condições básicas para o surgimento da futurologia, entendida como "ciência do futuro". 
Outra representação cronológica é dada por Barbieri (1993 apud GÜELL, 2004), considerando período, terminologia e autores envolvidos na evolução do tema: 1950 - Previsão Tecnológica (Kahn, Helmer, Daddario); 1960 - Previsão Sociológica (Mchale, Toffler, Fuller); 1970 - Previsão Global - (Forrester, Meadows); 1980 - Prospectiva (Berger, Massé, Godet); 1990 - Programas de Prospecção (Ministério da Indústria e Tecnologia do Japão - MITI); 2000 Observatório de Prospectiva (Tecnológica e Setorial).

Em 1972, o Office of Technology Assessment (OTA), nos Estados Unidos, constatou que a tecnologia muda e se expande rápida e continuamente, que suas aplicações são amplas e em escalas crescentes, cada vez mais generalizadas e críticas em seus impactos, benefícios e problemas em relação ao ambiente social. Passou a ser essencial que as consequências das aplicações tecnológicas sejam antecipadas e consideradas na determinação das políticas públicas em problemas existentes e emergentes (BLAIR, 1994). Ao longo da década de 90 , a prospecção tecnológica adquiriu um lugar de destaque porque propicia a geração de opções relativas à ciência e tecnologia e promove uma vinculação mais estreitas dessas à inovação, à criação de riqueza e a uma melhor qualidade de vida (JOHNSTON, 2001).

No século XXI proliferaram estudos em vários países, sob diversos enfoques. Alguns destaques envolvem estudos acerca de interesses estratégicos nacionais; geração de políticas tecnológicas; desenvolvimento regional e de aglomerados produtivos; trajetórias tecnológicas em segmentos específicos etc. Dada a amplitude desse tema, o assunto será abordado oportunamente, em outros trabalhos.

Por fim, como pauta emergente, evidencia-se o trabalho de Sardar (2010), que propõe quatro leis de estudos do futuro, preconizando, em essência, que o tema não seja tratado como disciplina com fronteiras rígidas, teorias fixas, terminologia esotérica ou foco em supostos "fundadores" desta seara.

\section{Metodologia}

Uma vez determinado o objeto de estudo, foram definidos os procedimentos metodológicos adequados para a realização da análise proposta. É o que então se apresenta, enfatizando-se os aspectos filosóficos e instrumentais.

De acordo com Severino (2000), um ensaio teórico consiste na exposição lógico-reflexiva com ênfase na argumentação e interpretação pessoal.

Diante disso, observa-se que a pesquisa iniciou-se mediante a busca de dados secundários, por meio de pesquisa bibliográfica, quando se priorizou a consulta a obras de autores considerados referência sobre o tema proposto. Esta opção permitiu discutir os conceitos relacionados aos estudos do futuro, apresentando as diversas nomenclaturas e abordagens encontradas até então na literatura, bem como caracterizar suas relações.

Neste processo, de acordo com a recomendação de Cervo e Bervian (2002), adotou-se a seguinte abordagem: visão sincrética - leitura de reconhecimento que tem o propósito de localizar fontes, em uma aproximação preliminar sobre o tema; visão analítica - leitura crítico/reflexiva dos textos selecionados; visão sintética - interpretativa e de síntese.

Essa visão sincrética permitiu a construção de um quadro analítico, que apresenta uma organização ou agrupamento dos conceitos discutidos, a partir das abordagens dadas pelos autores pesquisados.

As etapas transcorridas nessa análise podem ser sintetizadas da seguinte forma: i) identificação do problema e definição do objetivo de pesquisa (com delimitação de abordagem); ii) definição dos construtos a serem pesquisados (abordagens, definições e evolução histórica dos estudos futuros), aprofundando a contextualização do tema e orientando o recorte temporal enfocado; iii) definição de palavras-chave (estudos do futuro; prospectiva; prospecção; previsão; cenários futuros etc.), e seleção de referências significativas, a partir das quais foi construída a fundamentação teórica, permitindo o detalhamento conceitual e cronológico das terminologias associadas; iv) identificação dos autores de referência (e suas escolas) no tema de interesse; v) organização e discussão sobre os conceitos; vi) desenvolvimento da análise crítica, a partir de leitura sincrética, analítica e sintética, para assim constituir o Quadro 3 e a Figura 1.

A análise envolvida considerou como variáveis operacionais: a escola do autor considerado; as referências por ele utilizadas; a abrangência e/ou profundidade da definição considerada; as ferramentas metodológicas associadas a cada conceito (pelos autores); os resultados e impactos obtidos em cada aplicação relatada; e a coerência de discurso entre os aspectos anteriores, vista de forma transversal entre os autores.

O estudo também pode ser caracterizado por sua finalidade descritiva, por enfocar a descrição das características de determinada população ou fenômeno, ou o estabelecimento de relações entre variáveis (GIL, 1999), neste caso, conceitos e definições.

Finalmente, e considerando o caráter teórico da pesquisa, ressalta-se que a mesma também se utilizou dos princípios do método dialético (SILVA; MENEZES, 2005), a partir do qual as definições foram confrontadas na tentativa de encontrar semelhanças (coerência) e diferenças (inconsistências relativas).

\section{Análise crítica}

Conhecidos os conceitos sobre os estudos do futuro e as diversas definições e abordagens adotadas pela comunidade científica, apresenta-se a seguir, conforme os objetivos deste trabalho, a discussão e análise comparativa já mencionada, de modo a resultar na construção e indicação de uma terminologia clara e adequada às aplicações brasileiras. Na sequência, 
indica-se uma organização cronológica dessas mesmas abordagens.

\subsection{Análise comparativa das terminologias associadas aos estudos do futuro}

Muitos estudos têm tratado indistintamente os conceitos relacionados aos estudos do futuro. Mesmo em traduções, sinônimos literais nem sempre representam a melhor opção.

Alguns autores consideram que future studies e foresight estariam mais correlacionados a estudos classificados como mais intuitivos, baseados em opinião de especialistas, cobrindo um espectro mais amplo de aplicações, enquanto forecasting estaria mais fundamentado em técnicas quantitativas.

Em contrapartida, quando se analisa um pouco mais detalhadamente o uso dos termos, a conclusão é que foresight e forecasting vêm sendo usados por diversos autores com o mesmo significado. É bastante comum a alternância dos termos num mesmo trabalho. Isto é corroborado pela afirmação feita por Coates et al. (2001, p. 1) quando dizem que

“[...] não se pretende nenhuma distinção entre technological forecasting, technology forecasting ou technology foresight, exceto quando especificamente descrito no texto".

Outro exemplo de uso desses termos com o mesmo sentido está no Japão. Embora os estudos de caráter nacional sejam teoricamente foresighting, foram chamados de forecasting.

No intuito de correlacionar os conceitos discutidos, apresenta-se no Quadro 3 a síntese da visão proposta neste trabalho, baseada na análise comparativa dos termos supracitados.

$\mathrm{O}$ agrupamento de conceitos variados em uma dada categoria analítica (ou abordagem, conforme o Quadro 3) decorre essencialmente da semelhança das finalidades desejadas e métodos utilizados na antecipação do futuro. Considerou-se para isso, por análise de discurso da literatura consultada, a abrangência do conceito, as técnicas aplicadas nos estudos, os resultados atingidos e a pertinência da aplicação de traduções literais para o idioma português.

Isso implica em que futuribles e cenários constituam uma categoria conceitual significativamente diversa das demais, pois se apresentam mais como ferramentas ou resultados do que como processo. Ainda, cabe diferenciar a ideia de que ao passo que foresight e forecast referem-se a abordagens ou a conjuntos específicos de métodos utilizados na investigação do futuro, foresighting e forecasting estariam mais aderentes à narrativa do processo.

Expressões como technological, technology ou regional, por vezes associadas aos estudos do futuro, figuram apenas como delimitadores de escopo da pesquisa, indicando o segmento técnico, econômico ou social de maior interesse em cada caso. Quanto a isso, já há maior coerência na literatura, não merecendo maiores considerações por parte deste trabalho, também por conta de que traduções literais são pertinentes.

Embora alguns autores (entre eles Godet) considerem a prospecção ou foresight como metodologias menos pró-ativas que a prospective, nas quais o foco está na possibilidade de atuar na conformação do futuro, diversas outras opiniões

Quadro 3. Análise das abordagens relacionadas aos estudos do futuro.

\begin{tabular}{|c|c|}
\hline Terminologias & Abordagens \\
\hline Estudos do futuro & \multirow{2}{*}{$\begin{array}{l}\text { Termos genéricos que englobam todos os estudos e métodos elaborados na tentativa de } \\
\text { antecipar ou construir o futuro. }\end{array}$} \\
\hline Future studies & \\
\hline $\begin{array}{l}\text { Antecipação e } \\
\text { previsão }\end{array}$ & \multirow{2}{*}{$\begin{array}{l}\text { Ambos veem o futuro como um porvir tendencial, que pode ser analisado por meio de } \\
\text { séries históricas, aplicando-se ferramentas matemáticas. Quanto mais confiáveis forem } \\
\text { as bases de dados e mais amplo o período de tempo que elas contêm registros, mais } \\
\text { confiável será a extrapolação. De qualquer forma, cabe ressaltar que exercícios dessa } \\
\text { natureza não garantem necessariamente uma boa aproximação do futuro que irá se } \\
\text { concretizar, apenas uma visão provável. }\end{array}$} \\
\hline Forecast(ing) & \\
\hline Prospecção & \multirow{4}{*}{$\begin{array}{l}\text { Os métodos dessa categoria são aqueles que priorizam abordagem qualitativa na análise } \\
\text { do futuro, tendo como principal objetivo a coesão de esforço dos envolvidos na definição } \\
\text { do futuro desejado e na conjugação de esforços para torná-lo exequível. Visam identificar } \\
\text { elementos para a melhor tomada de decisão, levando em consideração aspectos econômicos, } \\
\text { sociais, ambientais, científicos e tecnológicos, sendo frequentemente associados à grande } \\
\text { temporalidade. Dessa forma, apresentam viés exploratório ou normativo, no qual a reflexão } \\
\text { coletiva sobre os desafios futuros conduzem à definição de opções estratégicas. }\end{array}$} \\
\hline Prospectiva & \\
\hline Foresight(ing) & \\
\hline La Prospective & \\
\hline $\begin{array}{l}\text { Technology } \\
\text { assessment }\end{array}$ & \multirow{2}{*}{$\begin{array}{l}\text { São mais focados na análise de impacto das tecnologias vigentes e futuras, adotando } \\
\text { uma postura mais de "radar" do que de "ação". Para isso, acompanham a trajetória } \\
\text { tecnológica, antecipando alternativas e consequências. }\end{array}$} \\
\hline Veille technologique & \\
\hline Futuribles & \multirow{2}{*}{$\begin{array}{l}\text { Dizem respeito aos futuros possíveis ou prováveis, constituindo-se em ferramentas no } \\
\text { processo de investigação do futuro. Assim, não devem ser confundidos ou tomados na } \\
\text { mesma medida dos demais conceitos. }\end{array}$} \\
\hline Cenários & \\
\hline
\end{tabular}

Fonte: Elaborado pelos autores. 
expressam o contrário, o que fica explícito, inclusive, na forma como definem esses conceitos.

Na prática, além das especificidades de objetivos, restrições orçamentárias ou disponibilidade de competências podem induzir à adoção de um ou outro enfoque e, portanto, uma ou outra terminologia.

\subsection{Delimitação do uso das diversas expressões relacionadas ao tema}

Identifica-se que nenhum método ou técnica relacionado a estudos do futuro pode responder a todos os questionamentos que envolvem um exercício prospectivo, de modo a atender à expectativa por antecipar o futuro. A análise prospectiva conduz à percepção e compreensão, de forma sistemática, do comportamento de variáveis do ambiente organizacional, relevantes para a definição de rumos e estratégias institucionais. A integração de mais de um método ou técnica na estrutura metodológica de um exercício prospectivo tende a reduzir os níveis de incerteza inerentes a essa atividade.

Cada um dos métodos, técnicas ou ferramentas, sejam de características quantitativas (tendenciais) ou qualitativas (prospectivas), apresentam vantagens e desvantagens. Nesse sentido, ressalta-se que os métodos quantitativos (forecast) se defrontam com a necessidade de séries históricas confiáveis ou da existência de dados coletados ao longo de um período razoável de tempo, se tornando vulneráveis a mudanças bruscas ou descontinuidades. Por outro lado, os métodos qualitativos (foresight) muitas vezes têm problemas decorrentes do limite do conhecimento dos atores, de suas preferências pessoais e parcialidades.

Assim, a cada caso, os resultados esperados, os recursos disponíveis e o perfil das fontes de informação (documentais ou pessoais) devem orientar a abordagem predominante e, por conseguinte, o instrumental metodológico utilizado.

\subsection{Evolução dos estudos do futuro - uma cronologia temática}

Partindo das referências já citadas, e incluindo ainda Masini (1993), Godet (1993) e Amsteus (2008), propõe-se uma reorganização dos eventos relacionados à temática em estudo, de modo a permitir uma visualização facilitada da sua evolução, explicitando alguns autores associados a ela, e da cronologia das variações conceituais. É o que mostra a Figura 1.

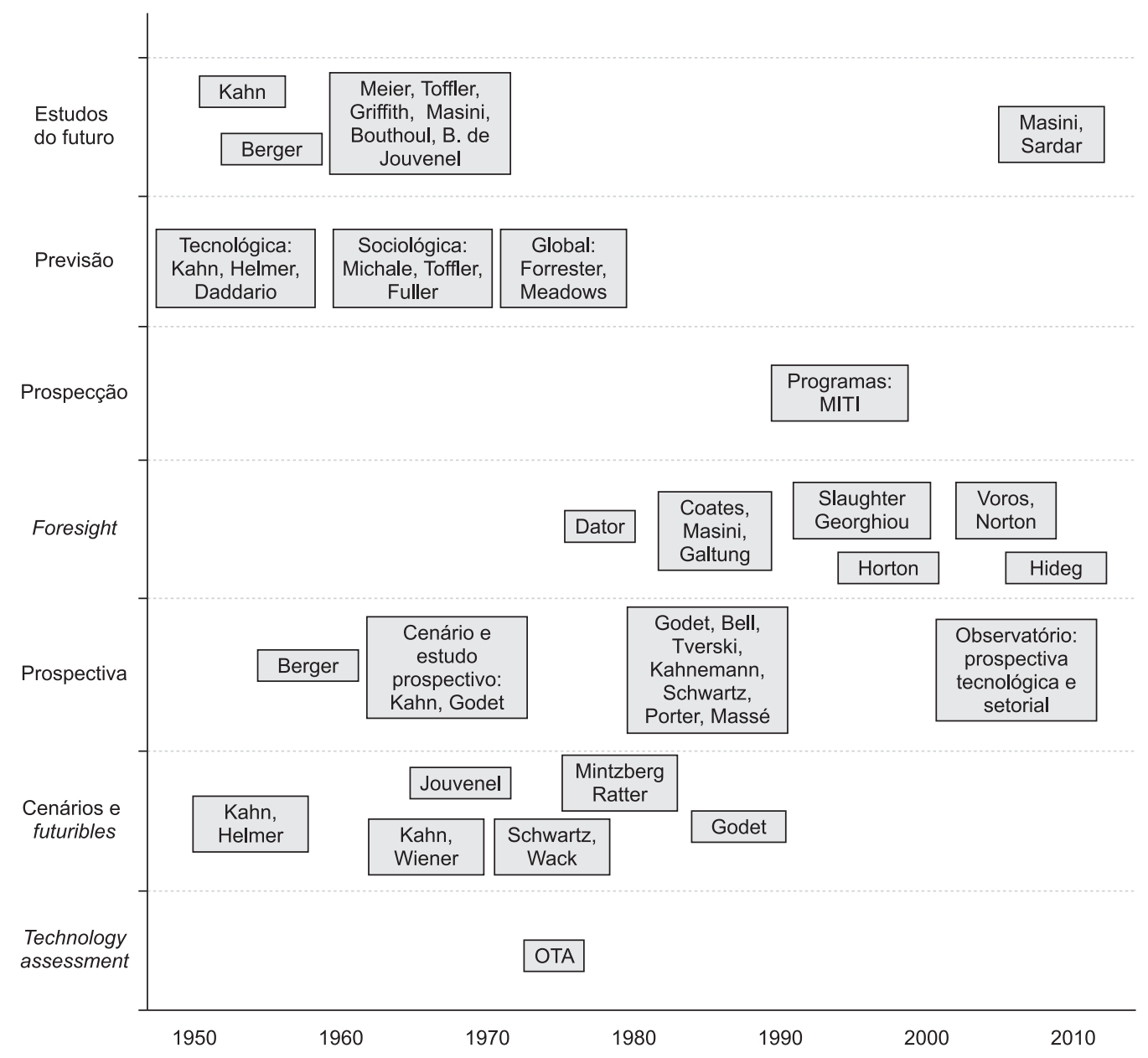

Figura 1. Cronologia da evolução do tema estudos do futuro. Fonte: Elaborado pelos autores. 
Como já argumentado, os estudos do futuro têm origens remotas e evolução contínua ao longo da história. No entanto, o tratamento mais genérico tem sido substituído por visões mais específicas, relacionadas a métodos próprios de investigação e construção do futuro.

Desses, pode-se observar que a prospectiva desenvolveu-se paralelamente à ideia de cenários. Embora essas conceituações/nomenclaturas tenham surgido ainda na década de 50, sofreram diversas contribuições, atualizando-se e ganhando maior especificação e complexidade operacional, mantendo-se em pauta no meio científico até os dias de hoje. Suas aplicações são variadas em escopo e encontradas em diversas nacionalidades.

O mesmo ocorre com a proposta do foresight. Embora ganhando maior sistematização na década de 80 , suas aplicações têm se expandido e se tornado cada vez mais frequentes no planejamento de ciência e tecnologia das nações e de segmentos específicos da indústria. Atualmente, o foco está mais voltado aos benefícios do processo em si, enquanto articulador de agentes, do que nos resultados objetivos atingidos em termos de antecipação do futuro. Uma metanálise de casos permite concluir que a maioria dos esforços é relacionada à prospectiva tecnológica, ou foresight tecnológico.

A abordagem de previsão ou forecast também tem sido aplicada a diversos segmentos da economia e da sociedade, buscando dar suporte para o desenvolvimento tecnológico e social. A variedade de metodologias que tem sido desenvolvidas e empregadas em forecast nas últimas décadas visa ampliar a precisão dos estudos, como resposta às críticas dos adeptos da prospecção e prospectiva, mais qualitativos. O caráter quantitativo do forecast, no entanto, permite o estabelecimento de métodos mais replicáveis e comparáveis entre si, viabilizando a possibilidade de uma recomendação mais específica para cada contexto de aplicação.

\section{Considerações finais}

Muito se escreve sobre a compreensão do futuro como ferramenta indispensável e poderosa para os gestores que buscam tornar suas organizações ainda mais competitivas. A temática incorporou-se ao dia a dia de muitas organizações e, apesar de um considerável volume de informações sobre o tema, estabelecer um arcabouço conceitual adequado à aplicação no cenário científico brasileiro é um desafio não tão simples de ser definido, mesmo porque, a realização efetiva e de forma estruturada e contínua de estudos sobre o futuro é uma atividade relativamente recente no Brasil e no mundo. Além disso, esses estudos transcorrem hoje num contexto de mudanças profundas no cenário internacional, ampliando sua relevância, mas também dificultando sua realização e/ou obtenção de resultados mais seguros.

Como primeira conclusão, evidencia-se que a terminologia relacionada aos estudos do futuro tem sido aplicada indistintamente, ora com o mesmo significado, ora com conotações e aplicações significativamente diferentes. Assim, ratifica-se que a expressão "estudos do futuro" seja adotada como generalizadora, englobando todas as abordagens e metodologias científicas relacionadas à tentativa sistemática de antecipar ou construir o futuro.

Pode-se resumir em três principais momentos a evolução dos estudos do futuro: século V ao XIII - magos e feiticeiros se utilizavam da adivinhação; séculos XVII e XVIII - ciências matemáticas e estatísticas fundamentaram os estudos tendenciais (forecast); final da década de 50 - proposta multidimensional e humanista estruturou os estudos prospectivos (foresight).

Percebe-se a preocupação do homem em tentar antecipar o futuro desde a reminiscência da Idade Antiga até os dias atuais. Ressalte-se que, no princípio, havia um tanto de introspecção e imaginação. Com a evolução dos tempos, os métodos utilizados ganharam credibilidade, pois passaram a apresentar maior pertinência, coerência e replicabilidade.

Os estudos do futuro seguem duas grandes vertentes: previsão - foco quantitativo; prospecção - foco qualitativo. A previsão caracteriza-se por construir um futuro à imagem do passado, enquanto que a prospecção orienta-se para um ou vários futuros. A previsão apresenta relações estáticas, estruturas fixas; já a prospecção apresenta relações dinâmicas, estruturas em evolução, com foco na tomada de decisão e construção do futuro desejado.

Embora o termo previsão faça parte também de um contexto de linguagem popular, é o conceito que melhor representa, no contexto do Brasil, os estudos quantitativos tendenciais, tratados internacionalmente como forecast. Por outro lado, prospecção e prospectiva correspondem, respectivamente, aos termos foresight e prospective, podendo ser usados indistintamente. Deixe-se claro que, a rigor, podem utilizar métodos parcialmente diferentes, mais adequados a cada contexto de aplicação. Essas definições metodológicas decorrem, por exemplo, da amplitude temporal do exercício prospectivo, do setor de investigação, e da composição (tamanho do grupo, multidisciplinaridade e estrutura de poder) dos stakeholders.

O método de cenários deve ser entendido exatamente desta forma: como técnica que se pode lançar mão durante a elaboração de um estudo prospectivo. Sua finalidade é auxiliar na composição de futuros possíveis, não necessariamente associando-se a eles qualquer relação de probabilidade de ocorrência.

Acredita-se que este estudo apresentou conceitos e pressupostos considerados referência na temática, que 
dão suporte à construção das proposições apresentadas e à organização da trajetória histórica a respeito do tema.

Como oportunidades de pesquisas futuras, sugere-se uma investigação das origens dos estudos prospectivos no Brasil, visando melhor explicitação e apropriação dos significados subjetivos à adoção de termos e métodos, inerentes à expressão cultural de outra localidade. Também, um levantamento analítico de aplicações de estudos prospectivos realizados no Brasil, visando identificar casos de referência, melhores práticas e temáticas desenvolvidas.

Espera-se com isso que erros conceituais possam ser superados a partir do uso amplo de uma terminologia mais adequadamente aplicada. Partindo disso, novas pesquisas podem fundamentar-se em um arcabouço conceitual mais consistente e mais coerente, implicando numa melhor definição de metodologias específicas e, por conseguinte, atingindo melhores resultados nas aplicações práticas. Desse modo, análises comparativas de resultados podem ser levadas a cabo, sustentadas por um discurso coerente e pela confrontação de informações baseadas em critérios pertinentes às metodologias aplicadas a cada caso.

\section{Referências}

AMARA, R.; SALANIK, G. Forecasting: from conjectural art toward science. Technological Forecasting and Social Change, v. 3, n. 3, p. 415-426, 1972. http:// dx.doi.org/10.1016/S0040-1625(71)80029-X

AMSTEUS, M. Managerial foresight: concept and measurement. Foresight, v. 10, n. 1, p. 53-66, 2008. http://dx.doi.org/10.1108/14636680810856026

BERGER, G. Phénoménologie du temps et prospective. Paris: PUF, 1964.

BLAIR, P. Technology assessment: current trends and the myth of a formula. 1994.

BODINI, V. L. Uso da análise estrutural prospectiva para a identificação de fatores condicionantes da competitividade na agroindústria brasileira. 2001. Tese (Doutorado em Engenharia de Produção)-Universidade Federal de Santa Catarina, Florianópolis, 2001.

BORJESON, L. et al. Towards a User's Guide to Scenarios: a Report on Scenario Type and Scenario Techniques. Environmental Strategies Research. Stockholm: Royal Institute of Technology, 2005. Disponivel em: <http:// www.infra.kth.se/fms>. Acesso em : 05 set. 2006.

BOUVIER, Y. Une histoire de la prospective. Paris: Sorbonne, 2002. Disponivel em: <http://www.paris4. sorbonne.fr/html/recherche/ecol_et_cen/moderne/crhi/ pub4.htm>. Acesso em: 21 jan. 2003.

CAMARGO, O. Uma contribuição metodológica para planejamento estratégico de corredores de transporte de carga usando cenários prospectivos. 2005. Tese (Doutorado em Engenharia de Produção)- Universidade Federal de Santa Catarina, Florianópolis, 2005.

CERVO, A. 1.; BERVIAN, P. A. Metodologia científica. 5. ed. São Paulo: Prentice Hall, 2002.

CHRISPINO, A. Cenários futuros e cenários para educação: um exemplo aplicado à educação média. 2001.
Tese (Doutorado em Educação)-Universidade Federal do Rio de Janeiro, Rio de Janeiro, 2001.

COATES, J. A. Foresight in federal government policy making. Futures Research Quartely, v. 1, p. 29-53, 1985.

COATES, J. Why Study the Future? Research Technology Management, 2003.

COATES, V. et al. On the future of technologial foresight. Technological Forecasting and Social Change, v. 67, n. 1, p. 1-17, 2001. http://dx.doi.org/10.1016/ S0040-1625(00)00122-0

CRISTO, C. M. Prospectiva estratégica: instrumento para a construção do futuro e para a elaboração de políticas públicas. In: CONGRESSO INTERNACIONAL DEL CLAD SOBRE LA REFORMA DEL ESTADO Y DE LA ADMINISTRACION PUBLICA, 7., 2002, Lisboa. Anais... Lisboa, 2002.

CUHLS, K.; GRUPP, H. Status and prospects of technology foresight in Germany after ten years. 2001. Disponivel em: <http://www.nistep.go.jp/achiev/ftx/eng/mat077e/ html/mat077ae.html>. Acesso em: 26 mar. 2010.

FORESIGHT FOR REGIONAL DEVELOPMENT NETWORK - FOREN. A Practical Guide to Regional Foresight. European Communities, 2001. 132 p.

FUNDACIÓN COTEC. Tendências Tecnológicas en Europa. Análisis de los procesos de prospectiva. Madrid: COTEC, 2003. $134 \mathrm{p}$.

GIL, A. C. Métodos e Técnicas de Pesquisa Social. 5. ed. São Paulo: Atlas, 1999.

GLENN, J. C. Introducción a la serie de metodología de investigación de futuros (tradução). In: GLENN, J. C. Futures Research Methodology. Buenos Aires, 2004. Disponivel em: <http://zulia.colciencias.gov.co/portalcol/ downloads/archivosContenido/93.pdf>. Acesso em: 16 nov. 2006.

GODET, M. From Forecasting to "La Prospective": a New Way of Looking at Futures. Jounal of forecasting, v. 1, n. 3, p. 293-301, 1982.

GODET, M. Introduction to la prospective: seven key ideas and one scenario method. Futures, p. 134-157, 1986.

GODET, M. Manual de prospectiva estratégica: da antecipação à acção. Lisboa: Dom Quixote, 1993. 405 p.

GODET, M. "A caixa de ferramentas" da prospectiva estratégica. Lisboa: Centro de Estudos de Prospectiva e Estratégia, 2000. (Caderno, n. 5).

GODET, M. Manuel de prospective stratégique: tome 1 une indiscipline intellectuelle. 2. ed. Paris: Dunod, 2001.

GODET, M. Manual de prospectiva estratégica: da antecipação à acção. Lisboa: Dom Quixote, 2003.

GODET, M.; ROUBELAT, F. Creating the future: the use and misuse of scenarios. Long Range Planning, v. 29, n. 3, p. 164-171, 1996. http://dx.doi. org/10.1016/0024-6301(96)00004-0

GONÇALVES, P. C. et al. Construção de Cenários para o Setor Hospitalar: Um Estudo no Estado de São Paulo. In: SIMPÓSIO DE EXCELÊNCIA EM GESTÃO E TECNOLOGIA, 4., 2007, Resende. Anais... Rio de Janeiro: SEGeT, 2007.

GORDON, T. J. Integración de los de pronóstico y fronteras de la investigación de futuros. Buenos Aires: BCNA, 2004.

GRONDONA, M. ¿Hacia dónde vuelan las aves? Arquivo de artigos, ETC, 2007. Disponivel em: <http://arquivoetc. 
blogspot.com/2007/10/hacia-dnde-vuelan-las-avespormariano.html>. Acesso em: 26 mar. 2010.

GÜELL, J. M. F. El diseño de escenarios en el ámbito empresarial. Madrid: Ediciones Pirâmide, 2004, 176 p.

HORTON, A. Foresight: how to do simply and successfully. Foresight, v. 1, n. 1, 1999. http://dx.doi. org/10.1108/14636689910802052

INSTITUTO NACIONAL DE TECNOLOGIA - INT. Nota técnica 14 - Prospecção tecnológica: metodologias e experiências nacionais e internacionais. Rio de Janeiro: INT/ANP, 2003. 99 p. Projeto CTPETRO.

JAGUARIBE, H. Brasil e mundo na virada do século. Dados, v. 39, n. 3, 1996. Disponivel em: $<$ http://www.scielo.br/scielo.php?script=sci_ arttext\&pid=S0011-52581996000300002>. Acesso em: 13 abr. 2010.

JOHNSON, B. B. Cenários para o Planejamento. In: JANTSH, E. Perspectives of Planning. Paris: OCDE. 1969. 372 p.

JOHNSTON, R. Experiências Nacionais de Estudos Prospectivos: Reflexões da Austrália. Revista Parcerias Estratégicas, n. 10, p. 124-144, 2001.

JOUVENEL, H. A brief methodological guide to scenario building. Technological Forecasting and Social Change, v. 65 , n. 1, p. 37-48, 2000. http://dx.doi.org/10.1016/ S0040-1625(99)00123-7

KUPFER, D.; TIGRE, P. B. Prospecção tecnológica. In: CARUSO, L. A.; TIGRE, P. B. (Coords.). Modelo SENAI de prospecção: documento metodológico. Montevideo: CINTERFOR/OIT, 2004. 77 p. (Papeles de la Oficina Técnica, n. 14).

LIMA, S. M. V. et.al. Projeto Quo Vadis, O Futuro da Pesquisa Agropecuária Brasileira. Brasília: Embrapa Informação Tecnológica, 2005. 451p.

LINSTONE, H. A.; GRUPP, H. National technology foresight activities around the globe: resurrection and new paradigms. Technological Forecasting and Social Change, v. 60, p. 85-94, 1999. http://dx.doi.org/10.1016/ S0040-1625(98)00039-0

MARCIAL, E. C.; GRUMBACH, R. J. S. Cenários prospectivos: como construir um futuro melhor. 4. ed. Rio de Janeiro: FGV, 2006.

MARINHO, D. N. C.; QUIRINO, T. R. Considerações sobre o estudo do futuro. Sociedade e Estado, v. 10, n. 1, p. 13-49, 1995.

MASINI, E. Why Futures Studies? London: Grey Seal, 1993.

MASINI, E. B. A vision of futures studies. Futures, v. 34, n. 3-4 p. 249-259, 2002. http://dx.doi.org/10.1016/ S0016-3287(01)00042-8

MASINI, E. B. The past and the possible futures of futures studies: some thoughts on Ziauddin Sardar's "the namesake". Futures, v. 42, n. 3, p. 185-189, 2010. http://dx.doi.org/10.1016/j.futures.2009.11.002

MASINI, E. B; SAMSET, K. Recommendations of the WFSF General Assembly. WFSF Newsletter, p.15, 1975.

OBSERVATÓRIO DE DESENVOLVIMENTO INDUSTRIAL DE SANTA CATARINA - ODI/SC. Relatório das atividades do estudo prospectivo no arranjo produtivo local de tecnologia de informação e comunicação de Santa Catarina. Florianópolis: IEL/ SC, 2009. Relatório, n. 4.

OLIVEIRA, D. P. Estratégia empresarial e vantagem competitiva: como estabelecer, implementar e avaliar. São Paulo: Atlas, 2001.

PATOKORPI, E.; AHVENAINEN, M. Developing an abduction-based method for futures research. Futures, v. 41, n. 3, p. 126-139, 2009.

PORTER, A. et al. Forecasting and management of technology. New York: J. Wiley, 1991.

RATTNER, H. Estudos do futuro: introdução à antecipação tecnológica e social. Rio de Janeiro: FGV, 1979.

ROVEDA, C.; VECCHIATO, R. Foresight and innovation in the context of industrial clusters: The case of some Italian districts. Technological Foresight and Social Change, v. 75, n. 6, p. 817-833, 2008. http://dx.doi. org/10.1016/j.techfore.2008.03.004

SALLES FILHO, S. L. et al. (Coords.). Instrumentos de apoio à definição de políticas em biotecnologia. Brasília: MCT; Rio de Janeiro: FINEP, 2001.

SANTOS, N. M. G. Um estudo prospectivo sobre a previdência social brasileira. 2004. Tese (Doutorado em Ciências em Engenharia de Produção)-Universidade Federal do Rio de Janeiro, Rio de Janeiro, 2004.

SARDAR, Z. The Namesake: Futures; futures studies; futurology; futuristic; foresight - what's in a name? Futures, v. 42, n. 3, p. 177-184, 2010. http://dx.doi. org/10.1016/j.futures.2009.11.001

SCHNAARS, S. How to develop and use scenarios. Long Range Planning, v. 20, n. 1, p. 105-114, 1987. http:// dx.doi.org/10.1016/0024-6301(87)90038-0

SCHWARTZ, P. The art of the long view. New York: Doubleday, Currency, 1991.

SEVERINO, A. J. Metodologia do trabalho científico. 21. ed. São Paulo: Cortez, 2000.

SILVA, E.; MENEZES, E. Metodologia da pesquisa e elaboração da dissertação. 4. ed. Florianópolis: UFSC, 2005. 138 p.

WRIGHT, A. The Role of Scenarios as Prospective Sensemaking Devices. Management Decision, v. 43, n. 1, p. 86-101, 2005. http://dx.doi. org/10.1108/00251740510572506

ZACKIEWICZ, M.; SALLES FILHO, S. Technological Foresight - um instrumento para política científica e tecnológica. Revista Parcerias Estratégicas, Estudos Prospectivos, n. 10, p. 144-161, 2001. 